\title{
Hildebrando de Goes e sua leitura sobre História da Baixada Fluminense
}

\author{
History of Baixada Region by Hildebrando de Goes
}

\author{
Lúcia Helena Pereira da Silva \\ Universidade Federal Rural do Rio de Janeiro - UFRRJ - Seropédica - Rio de Janeiro - Brasil
}

\begin{abstract}
Resumo: O objetivo deste artigo é analisar o relatório da Diretoria de Saneamento da Baixada Fluminense publicado em 1939, procurando entender a história da Baixada Fluminense, construída por seu diretor Hildebrando de Góes. A leitura apresentada pelo chefe da Diretoria de Saneamento da Baixada Fluminense acabaria por constituir-se em história oficial e seria utilizada como chave de entendimento da região, inclusive delimitando-a territorialmente. Atualmente Baixada Fluminense é um conceito que serve para designar um pedaço de terra localizado na margem ocidental da baia de Guanabara. Termo inicialmente vindo da geografia, mudou o seu sentido ao longo do tempo e nas últimas cinco décadas remete a uma imagem que está intimamente ligada à pobreza, ao abandono dos poderes públicos, à ausência de estrutura urbana e à violência. O texto apresenta a conceito original de Hildebrando de Góes.
\end{abstract}

Palavras-chave: Baixada Fluminense. Saneamento. Administração Pública.

\begin{abstract}
This paper explores of the Department of Sanitation Baixada Fluminense' report, published in 1939, by director Hildebrando de Goes, to understand the history of the Baixada Fluminense Region. The reading presented by chief executive officer of the Department of Sanitation Baixada Fluminense Region go become the official story and was used as a key to be understanding the region, including the delimitation of the territory. Baixada Fluminense today is a concept which serves to designate lands located on the western shore of Guanabara Bay. Term originally coming from geography, changed your sense over time and over the past five decades refers to an image that is closely linked to poverty, abandonment of the public authorities, the absence of urban structure and violence. The article presents the original concept of Hildebrand de Goes.
\end{abstract}

Keywords: Baixada Fluminense Region. Sanitation. Public Administration. 


\section{Introdução}

Atualmente Baixada Fluminense é um termo que serve para designar um pedaço de terra localizado na margem ocidental da baía de Guanabara. Termo inicialmente construído pela Geografia para indicar um dado geográfico (a planície do estado do Rio de Janeiro), mudou seu sentido ao longo do tempo e nas últimas cinco décadas remete a uma imagem que está intimamente ligada à pobreza, ao abandono dos poderes públicos, à ausência de estrutura urbana e à violência de um território específico. Para dar conta do processo de construção desse imaginário que está atrelado ao termo, é necessário percorrer a história da ocupação daquelas terras e a atuação dos múltiplos agentes/sujeitos envolvidos nesse processo, entre eles o Estado, visto aqui através da Comissão/Diretoria de Saneamento chefiada pelo engenheiro Hildebrando Góes, criada em 1933.

A escolha da Diretoria, mais especificamente do relatório publicado em 1939 pelo chefe da repartição pública, deve-se à percepção de que a instituição estatal produziu um conjunto de enunciados que permitiu transformar aquele espaço, ao longo do tempo, em uma região. Não foi a Diretoria que construiu discursivamente a Baixada como periferia, mas produziu uma narrativa que possibilitou atrelar a imagem de pobreza àquelas terras, inclusive consolidando uma História, que mais tarde seria utilizada como principal instrumento de entendimento da região.

Ao mesmo tempo em que a Diretoria organizava um repertório acerca do território, efetuava obras que aumentariam as terras disponíveis que seriam ofertadas através da "febre de loteamento" (SOUZA, 1992), pois somente depois do saneamento da Baixada, na década de 1940, a região voltaria a ser integrada à cidade do Rio de janeiro, mas de forma subalterna como periferia

Região é aqui entendida como produto de uma maquinaria discursiva (PECHEUX, 2014) e não somente como conceito (da Geografia), já que é pensada "como algo fechado em si" que esconde a concorrência de "estoques de verdades" acerca de um determinado o território, apresentando-o como homogêneo e não como um campo de disputas de representações regionais.

O processo de metropolização da cidade do Rio de Janeiro teve como contrapartida o de periferização da Baixada e isto ocorreu em grande medida em função da atuação da Comissão/diretoria. Foi um processo multifacetado com dinâmicas diferenciadas, mas que ao fim e ao cabo transformou a região em lugar para "os de baixo", não só por liberar um grande estoque de terras, mas por fornecer elementos discursivos que possibilitaram criar um imaginário atrelado ao território que estava sendo ocupado de forma acelerada.

Ainda que se trate do estudo de uma região, objeto privilegiado da Geografia, é uma narrativa do campo da História, assim, para dar conta da proposta de entender como foi criada a repartição pública e como sua atuação, principalmente aquela apresentada no relatório, auxiliaram a constituir uma região periférica, a Baixada Fluminense. Desta forma, este texto está dividido em quatro partes, além da introdução. A segunda parte do texto tem objetivo de apresentar as comissões de saneamento que atuaram na região, o sentido da apresentação é mostrar que o relatório produzido em 1939 foi gestado em um longo processo de múltiplas temporalidades e sua produção carrega as marcas dessas temporalidades.

A terceira parte ilumina o contexto social-político de constituição da comissão chefiada por Hildebrando de Goes, na medida em que articula a conjuntura do Estado Novo às dinâmicas de metropolização do antigo Distrito Federal. A quarta parte apresenta o relatório confeccionado pelo engenheiro em 1939, não só por ser menos conhecido que o de 1934 (de 500 páginas), mas porque produzido durante o Estado Novo, esconde sob o discurso técnico, opções e posicionamentos políticos acerca da região, construindo uma História que seria popularizada anos mais tarde. A última parte procura analisar a leitura de Goes sobre a região, ainda que de forma preliminar, visto que os argumentos utilizados por ele foram utilizados exaustivamente a posteriori, acabando por naturalizar uma imagem da Baixada Fluminense. 


\section{As Comissões de Saneamento que atuaram na} Baixada Fluminense

Baixada Fluminense até a Comissão Federal de Saneamento da Baixada Fluminense de 1933 que depois transformou-se em Diretoria e mais tarde em Departamento, todos chefiados por Hildebrando Góes, era toda a planície que ocupava o estado do Rio de Janeiro; foi essa comissão que ratificou sua divisão em quatro seções: a dos Goitacás, a de Araruama, a da Guanabara e a de Sepetiba. A atual Baixada Fluminense ocupava espacialmente parte da então Baixada da Guanabara (que seria hoje a Região Metropolitana - RMRJ), termo atualmente em desuso, principalmente pelo sentido dado ao Fluminense, que a notabilizou como um "não-lugar", no sentido dado por Augé (2008)

Segundo Soares (1962), a região sempre estivera ligada à cidade do Rio de Janeiro, mesmo quando política-administrativamente tornara-se o grande município de Iguassu ${ }^{1}$ (em 1833), entretanto, segundo a autora, no final do século XIX, essa ligação sofreria grandes modificações, ocasionadas principalmente pelo recrudescimento das doenças endêmicas existentes no local, necessitando então da atuação das Comissões de Saneamento.

O fim do século iria, porém, assistir a uma profunda modificação nessas relações, decorrentes do estabelecimento das ligações ferroviárias com o interior e do crescente desinteresse da metrópole pela baixada que, abandonada aos próprios e parcos recursos e privada, pela abolição da escravidão, da mão-de-obra que lhe permitia, ainda, subsistir como zona agrícola, iria entrar numa decadência profunda. Aos poucos, o brejo e a malária tomaram conta daquela região, que, durante dois séculos, estivera tão ligada à cidade. O mato invadiu as estradas, os rios e canais entupiram-se com a falta de limpeza e de dragagem, as populações fugiram. A metrópole passou a

\footnotetext{
${ }^{1}$ O Uso da antiga grafia é por entender que Iguassu não é Nova Iguaçu. Nova Iguaçu é o atual município e Iguassu era o município que comportava o que é atualmente a região Baixada Fluminense. O termo corresponde a uma episteme e o sentido das palavras se realiza ao nível da profundidade de uma análise
}

ver na baixada uma ameaça a suas portas. O saneamento da baixada veio recolocar o recôncavo à disposição da metrópole, cuja progressão retomou a sua direção natural e histórica, possibilitando a reintegração dessa região à área metropolitana do Grande Rio de Janeiro e, o que é ainda mais importante, a ampliação do espaço urbano nesta direção. (SOARES, 1962, pp 176-177, grifo meu)

Parte da imagem que a Baixada tem atualmente, deve-se a uma ideia consolidada pela historiografia que estuda a região, e que Soares (1962) também ratifica. Essa literatura apresenta, resumidamente, a história do lado ocidental da baia de Guanabara da seguinte forma: até 1833 a região fazia parte do Termo da cidade do Rio de Janeiro e estava integrada economicamente à urbe. Entre 1833 e 1870, assumiria uma posição secundária na economia regional, entrando em decadência depois da Abolição, ocorrendo inclusive um vazio populacional em função das doenças endêmicas. Somente depois do saneamento, a Baixada na década de 1940, voltaria a ser integrada à cidade, mas de forma subalterna como periferia.

Esta leitura por muito tempo norteou o entendimento da região e vários autores, ainda que não colocasse isto como problema, acabaram por corroborar essa visão. As atuais pesquisas possibilitam novas interpretações acerca deste processo e, mesmo fugindo do escopo deste trabalho, é importante salientar que a inauguração da Estrada de Ferro Central do Brasil (inaugurada como Pedro II) e depois as demais ferrovias acentuaram essa imagem de região, vista como um lugar de passagem, transformando-a em um "não-lugar". As atuais pesquisas relativizam a interpretação vigente ao considerar também as dinâmicas locais.

A partir da década de 1870 , a região passaria a ser objeto de atenção do Estado Imperial e depois do republicano, essa preocupação seria mantida por razões que não estavam ligadas diretamente às dinâmicas econômicas (e sociais) locais. A Abolição não representou de forma homogênea a decadência

arqueológica da mesma, ainda que se considerem as classificações. Sobre a discussão dos significados sociais das palavras, ver MACHADO (2006). 
econômica da região e nem potencializou um vazio populacional como afirma a historiografia. A existência da citricultura em Jacutinga ainda que de forma incipiente na década de 1880 aponta para a interpretação que algumas partes da Baixada já estavam se reconfigurando economicamente com a agricultura voltada para exportação. Para Jacutinga (freguesia onde se localizava o povoado Maxambomba, depois cidade Nova Iguaçu) não houve
Maxambomba, depois cidade Nova Iguaçu) não houve vazio populacional, a freguesia e depois distrito no período em que malária foi eleita como principal obstáculo ao desenvolvimento da região manteve o crescimento populacional, embora em ritmo lento.

A criação de diversas Comissões de Saneamento foi um dos exemplos de como Estado passou a atuar na região. Assentado no tripé atenção às áreas por onde passavam as vias férreas, profilaxia

Figura 1. Mapa do Município de Nova Iguaçu em 1940

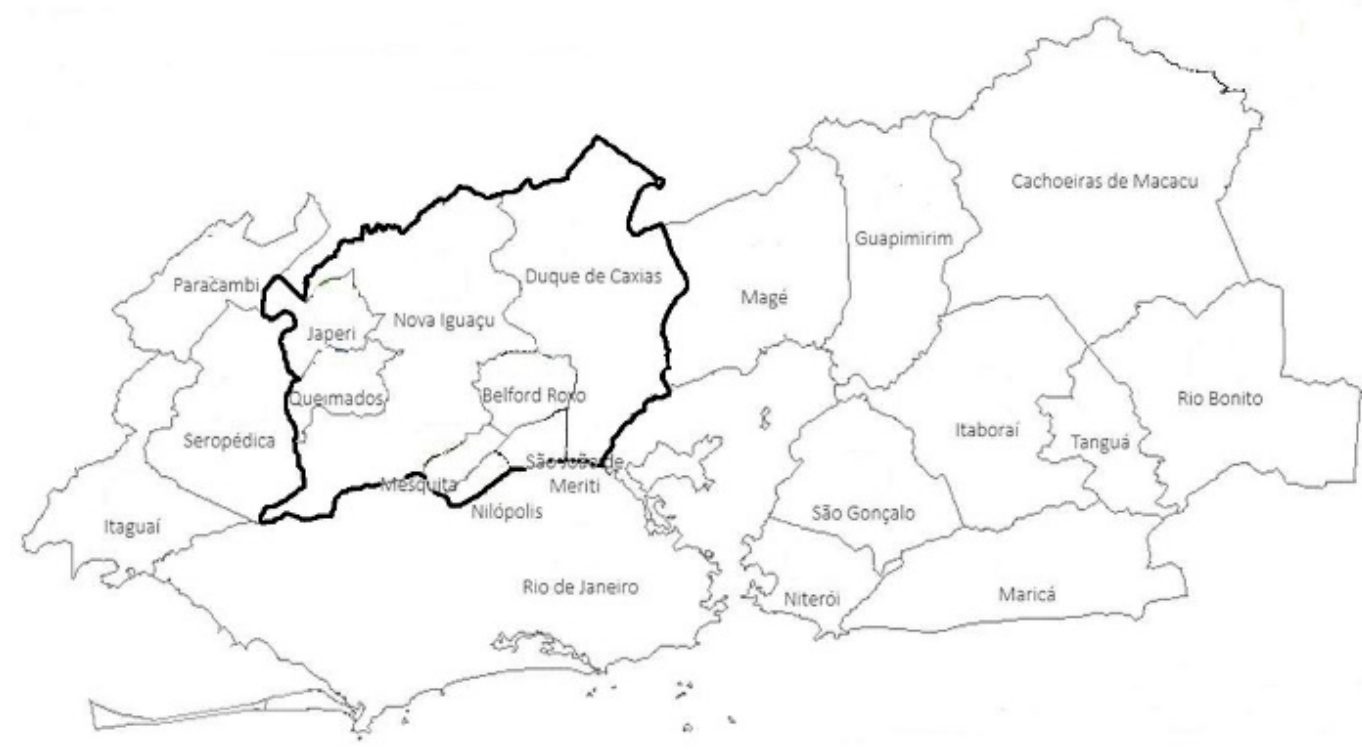

Mapa elaborado a partir das informações extraídas de MEDEIROS, 1946, p. 310 e segs

vazio populacional, a freguesia e depois distrito no período em que malária foi eleita como principal obstáculo ao desenvolvimento da região manteve o crescimento populacional, embora em ritmo lento.

A partir da década de 1870 , a região passaria a ser objeto de atenção do Estado Imperial e depois do republicano, essa preocupação seria mantida por razões que não estavam ligadas diretamente às dinâmicas econômicas (e sociais) locais. A Abolição não representou de forma homogênea a decadência econômica da região e nem potencializou um vazio populacional como afirma a historiografia. A existência da citricultura em Jacutinga ainda que de forma incipiente na década de 1880 aponta para a interpretação que algumas partes da Baixada já estavam se reconfigurando economicamente com a agricultura voltada para exportação. Para Jacutinga (freguesia onde se localizava o povoado das doenças e desenvolvimento da agricultura, os governos (estaduais e federais) intervieram na região. Antes da comissão federal de Hildebrando Góes, várias comissões estaduais atuaram na Baixada.

A primeira que se tem notícia foi a de 1883 ainda no Império, mas seria na República que as comissões de saneamento tornar-se-iam constantes. A primeira da República tinha o objetivo de intervir nas bacias hidrográficas do litoral de todo o estado, mas na prática centrou-se em duas regiões, na de Macaé/Campos e na da baia de Guanabara, próxima ao rio Pavuna, foi chefiada por Marcellino da Silva Ramos, o mesmo engenheiro da Comissão de Melhoramentos do Rio de Janeiro de 1874/76. 
Figura 2: mapa da planície do estado do Rio de Janeiro e suas subdivisões em 1939

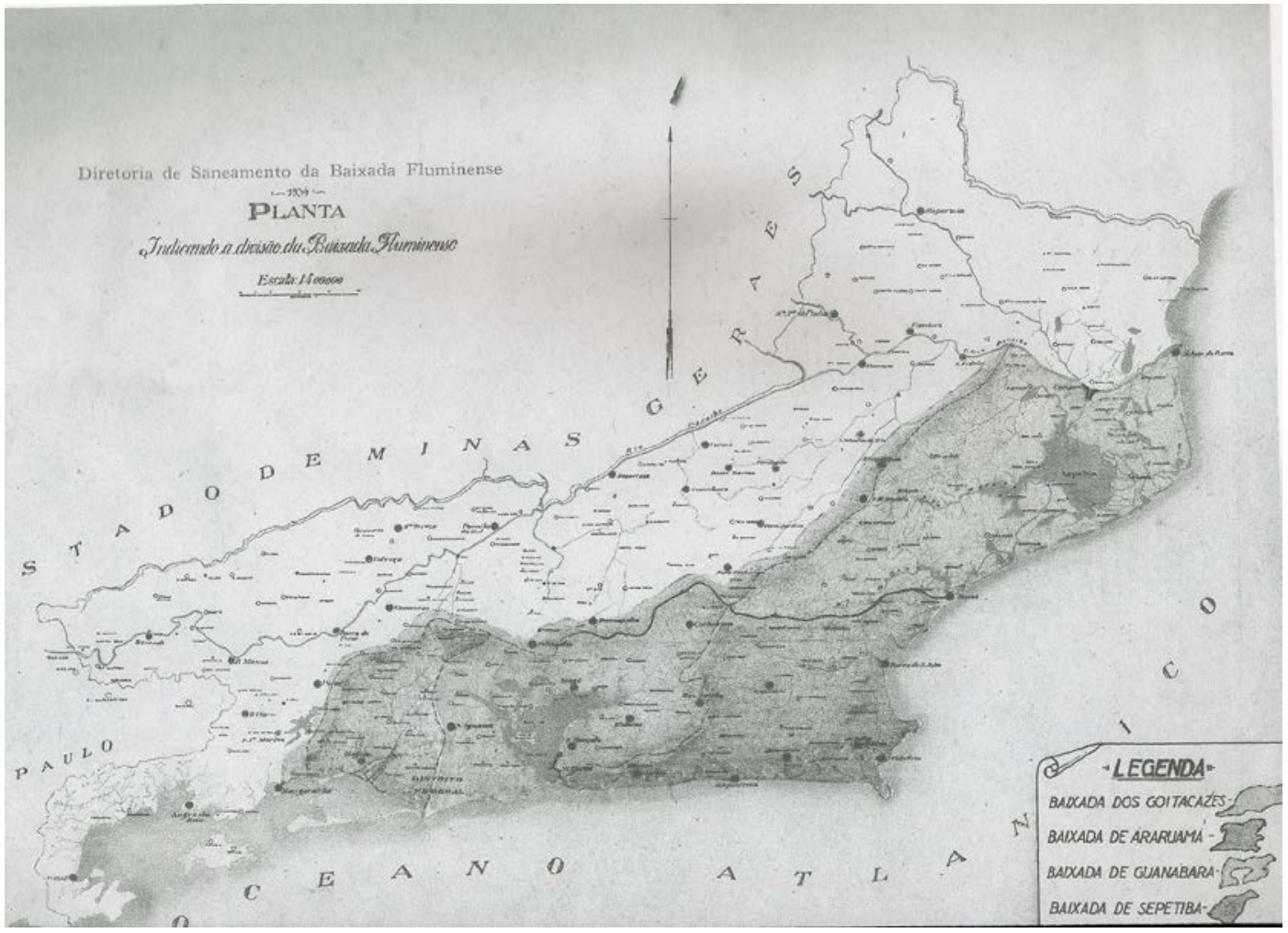

Fonte: Goes, 1939, p.3

Entre 1894 e 1900 vários estudos foram feitos na área que compreende os rios Inhomirim e Pilar, mas três fatores permitiram que a comissão permanecesse apenas na esfera dos estudos: o primeiro foi a reorganização administrativa da comissão que separou estudos de intervenções; havia a obrigatoriedade dos estudos estarem associados às sugestões de desenvolvimento econômico e como as chuvas de 1895 inundaram a Baixada Campista houve a necessidade de atuação do governo emergencialmente no dessecamento do local, na prática a Baixada Fluminense foi objeto de estudos minuciosos e sugestões, enquanto a Campista foi alvo das intervenções. O segundo fator foi a rotatividade dos trabalhadores da comissão, já que desde o primeiro ano de funcionamento, aproximadamente $40 \%$ do pessoal ficaram doentes. O terceiro fator foi a crise econômica provocada pelo Encilhamento, impedindo que o Estado realizasse grandes gastos.

A segunda comissão foi criada em 1902, incorporando duas ideias, uma construída como consenso pela primeira comissão: o saneamento o povoamento e desenvolvimento da região; mas diferente da primeira, buscava uma parceria com o governo federal, já que deixava claro que o saneamento da Baixada deveria ser pensada também como ação de profilaxia do Distrito Federal, incorporando a ideia de atuação conjunta com o governo federal, e foi essa intervenção conjunta que se tornou também consenso da comissão.

A saída de Quintino Bocayuva e a entrada de Nilo Peçanha no governo estadual mudariam a atuação do estado. O novo governador (naquela época presidente de estado) tinha o compromisso político de auxiliar os grandes proprietários rurais, em função da desorganização da produção que atingiu de forma mais drástica os fazendeiros fluminenses após a Abolição. A ajuda seria dada através de alocação de recursos financeiros ou de isenções tributárias, por conta disto não houve estímulo às atividades da comissão em função da crise financeira.

O sucessor de Nilo Peçanha, deixou de lado a comissão e firmou contrato com uma empresa japonesa com o intuito de facilitar a imigração dos 
mesmos. Os japoneses viriam trabalhar nas atividades de drenagem das terras da região e constituiriam três colônias agrícolas na Baixada: em Itaguaí, em Vila de Cava (Nova Iguaçu) e em São Bento (atual Duque de Caxias). O fracasso do empreendimento foi avaliado pelo executivo estadual (Alfredo Backer) como uma ação orquestrada pela oposição ao seu governo, já que iniciara seu governo com apoio de Nilo Peçanha e no final de seu mandato era-lhe então opositor.

A primeira Comissão Federal foi àquela constituída por Nilo Peçanha durante a sua breve passagem pela presidência da república em 1910. Essa Comissão chefiada inicialmente por Marcellino Ramos da Silva, depois de sua morte (25/12/1910) foi substituído pelo engenheiro Fabio H Moraes Rego. O mérito dessa Comissão foi o de consolidar as ideias que circulavam desde o final do século XIX em relação à Baixada Fluminense. Na década de 1910, ao mesmo tempo em que a região era conhecida pelas doenças, havia a expectativa dos governos estadual e federal em torná-la produtiva através do saneamento.

Ficou sob alçada da comissão a fiscalização do serviço de drenagem, pois a tarefa seria realizada pela empresa germano-holandesa Gebrueder - Goedhart A G. O contrato fixava o prazo de cinco anos para dessecar os pântanos da região. Com as terras saneadas o objetivo era torná-la apta à agricultura como era no século XVIII. A policultura permitiria construir um cinturão verde entorno da cidade do Rio de Janeiro, o projeto visava a constituição de uma vasta área para produção de farinha, milho, arroz, cana (açúcar) e banana, além de verduras e legumes nas proximidades do Distrito Federal.

A saída de Nilo Peçanha não interrompeu os trabalhos da Comissão Federal e com isto conseguiu consolidar a ideia de que as terras da Baixada eram férteis e necessitavam de duas ações: a extinção das doenças endêmicas, principalmente a malária, e o resgate das terras férteis para o uso da agricultura. $A$ concepção de sertão foi amplamente utilizada para designar a região, e uma forma de domar a natureza era ganhar as terras das águas para que pudessem ser utilizadas pela agricultura visando o abastecimento das duas capitais (Rio de Janeiro e Niterói). A utilização para a agricultura, vista como vocação da região, resultaria também no enriquecimento dos proprietários falidos.

A comissão estadual seguinte, organizada pelo correligionário de Nilo Peçanha, manteve inalteradas as principais ideias da comissão federal, aliás, ela passaria a ser utilizada como referência para a estadual, mas na prática tornou-se uma repartição de pequenas obras. Em 1914, Francisco Botelho informava em seu relatório anual as ações da Comissão Federal na Baixada em sua gestão, confirmando inclusive que o rio Pavuna voltara a ser navegável depois de muitos anos.

O mérito da Comissão Federal foi tornar incontestável a ideia de saneamento como instrumento civilizatório, agente de modernização e como suporte imprescindível à agricultura, extrapolando articulação recorrente entre saneamento e higiene. Entre 1910 e 1916 a Comissão Federal realizou um conjunto de estudos que apontou como um dos problemas de dessecamento das planícies embrejadas a existência de inúmeras linhas férreas cortando a região. A passagem das ferrovias exigia pontes que atuavam como diques que impediam o escoamento das águas, contrariando inclusive todos os esforços dos governos estaduais em associar ferrovias ao estímulo da produção agrícola e ao progresso. O último ano da comissão coincidiu com o segundo mandato de Nilo Peçanha a frente do governo do estado.

Saneamento, a partir do segundo mandato de Nilo Peçanha passou a ser utilizado como discurso de legitimação para maior controle das contas dos municípios e mais tarde abriria caminho para criação de prefeituras em municípios onde não existiam, aumentando sua força política no estado, como foi o caso da criação do executivo em Iguassu em 1919.

$\mathrm{Na}$ década de 1920, saneamento voltaria a ser articulado à profilaxia, sendo pensado em pequenas ações sob a alçada do Serviço de Malária do governo federal, enquanto obras relacionadas às redes de água e esgoto restritas ao governo estadual. Comissões de saneamento comandadas e executadas pela engenharia deixariam de ser utilizadas como instrumento de intervenção na Baixada 


\begin{tabular}{|c|c|c|c|}
\hline \multirow{3}{*}{$\begin{array}{l}\text { Ano } \\
1872\end{array}$} & Nova Iguaçu & D de Caxias & Nilópolis \\
\hline & $\begin{array}{l}\text { Freguesia de Jacutinga } \\
\text { (Com Nilópolis, Belford Roxo e } \\
\text { Mesquita) }\end{array}$ & $\begin{array}{l}\text { Município de Estrella } \\
\text { Freguesia de Pilar }\end{array}$ & $\begin{array}{c}\text { Paróquia de S } \\
\text { Mateus }\end{array}$ \\
\hline & 6546 & 3.533 & - \\
\hline \multirow[t]{2}{*}{1890} & $\begin{array}{l}\quad \text { Distrito de Jacutinga } \\
\text { (Com Nilópolis, Belford Roxo e } \\
\text { Mesquita) }\end{array}$ & Pilar & S Mateus \\
\hline & 6564 & 2.517 & - \\
\hline \multirow[t]{2}{*}{1920} & \begin{tabular}{l}
\multicolumn{3}{c}{ Nova Iguassu } \\
(com Belford Roxo e \\
Mesquita)
\end{tabular} & $\begin{array}{c}\text { Pavuna } \\
\text { (S João de Meriti) }\end{array}$ & Eng Neiva \\
\hline & 12.382 & 8.255 & 3.611 \\
\hline 1940 & $\begin{array}{l}\text { Nova Iguassu } \\
\text { (com Mesquita) }\end{array}$ & Caxias & Nilópolis \\
\hline & 34680 & 24.711 & 22341 \\
\hline
\end{tabular}

Movimentos diferentes sob auspícios da mesma política, o distrito de Nova Iguassu (Distrito sede) representou em parte o sucesso dessa política, já que o objetivo era o desenvolvimento agrícola da região, vista então como possível cinturão verde da metrópole que se formava. Na década de 1920 o processo de parcelamento do solo no município foi intenso, principalmente no distrito sede, nas localidades de Mesquita e Belford Roxo em função da produção cítrica estar assentada nas chácaras e não em latifúndios. As pequenas e médias propriedades dominavam a estrutura fundiária de toda a região.

Entre 1920 e 1940, Nova Iguassu (nas áreas supracitadas) e o bairro de Campo Grande no município do Rio tornaram-se grandes produtores de laranja, enquanto o distrito de Meriti urbanizava-se e era incorporado à malha urbana da metrópole, ficando conhecida como "Meriti do Pavor", em função das doenças produzidas pelos grandes charcos. A produção agrícola era escoada pela Central do Brasil e toda uma logística foi montada para a exportação da laranja. Em torno da estação surgiram vários barracões de beneficiamento e fábrica de caixas. Os laranjais espalhados pelas chácaras atraiam mão de obra do interior do estado e da Zona da Mata Mineira. As antigas estradas vicinais passaram a ser utilizadas pelos trabalhadores e para o escoamento da laranja. Somente Nilópolis teve ocupação urbana acelerada a partir da década de 1910, enquanto o restante do antigo distrito de Jacutinga manter-se ia rural.

O grande município chegava aos anos 1940 com duas dinâmicas: nas franjas, principalmente no $8^{\circ}$ Distrito (Caxias), intenso processo de ocupação urbana desordenada, enquanto no distrito de Nova
Iguassu experimentava o momento áureo da citricultura, onde o grupo político local investiu massivamente na estrutura urbana da sede municipal.

Politicamente dois grupos disputavam internamente o poder municipal com a hegemonia dos citricultores em detrimento do grupo de Caxias, formado por profissionais liberais e comerciantes locais. Quatro nomes dominaram a cena política local nas décadas de 1930 e 40: No âmbito local, Sebastião Arruda Negreiros como interventor municipal de 1930 a 1936, Getulio de Moura e Tenório Cavalcanti, ambos atuando na câmara municipal até 37; e Amaral Peixoto, interventor estadual de 37 a 45. Foi nesse cenário político que atuou a comissão/Diretoria chefiada por Hildebrando de Araújo Goes

Hildebrando de Araújo Goes, natural da Bahia, engenheiro formado pela Politécnica no Rio de Janeiro na década de 1920, não foi o primeiro chefe da comissão, que oficialmente foi instituída em 05 de julho de 1933 sob a chefia de Alfredo Conrado Niemeyer. A comissão teve existência pequena (33/35) e o único relatório conhecido, aquele apresentado em 1934 foi produzido por Hildebrando já no posto em que permaneceria até a transformação da comissão em diretoria em 1935.

Além do relatório, há informações da atuação da comissão na prestação anual de contas do ministro de viação e obras públicas (MVOP) e da Diretoria no relatório/livro de 1939. Este último será utilizado como fonte neste texto, principalmente por ser pouco conhecido. O relatório é um livro publicado pela Diretoria de Saneamento da Baixada Fluminense de autoria de seu diretor, Hildebrando. A narrativa ufanista tinha dois objetivos, primeiro fazer um balanço das realizações da Diretoria que substituiu a Comissão, e segundo, articular a diretoria ao ideário do Estado Novo.

Para o que cabe aqui e ainda nos apoiando em Albuquerque Junior (2009), o relatório é visto como espaço institucionalizado de produção de "verdade" que esconde o conflituoso embate de imagens e subjetividades. Isto ocorre principalmente por te sido produzido no interior de uma repartição pública, que ganha legitimidade exatamente por esconder, sob a 
forma de um discurso técnico, opções e posicionamentos políticos, sobretudo porque evoca uma identidade (sensibilidade) como ponto fixo de um discurso regionalista, esquecendo-se que é um discurso produtor de realidade, fruto de determinado contexto histórico. Isto significa dizer que o relatório deve ser entendido na articulação de três dimensões: a da política do Estado Novo, a da conjuntura política econômica social do estado do Rio de Janeiro e a do próprio ideário da engenharia.

\section{Hildebrando de Góes, uma história da Baixada Fluminense e a conformação de uma região}

Com 99 páginas, repleto de fotografia, o livro é o relato da atuação da Diretoria até o momento da publicação. A capa traz a imagem de Vargas e Amaral Peixoto pairando sobre as dragas e guindastes, estes últimos vistos como símbolos da modernidade que adentrava a região. Nas páginas seguintes são apresentados dois mapas, um da Itália e outro dos EUA, o primeiro comparando a superfície do território do estado do Rio com a largura do país europeu, o segundo informando a extensão da realização das obras de desobstrução dos rios. Os $3.800 \mathrm{~km}$ equivalem uma linha de costa a costa dos EUA, em um lugar cuja superfície era o da largura da Itália.

Não há palavras, só imagens, uma em cada página, a de uma fotografia montada e dois mapas, como se eles "por si só, falassem sozinhos", aliás, a narrativa escolhida é a da imagem, pois há mais fotografia que produção textual. O relatório está dividido em dois capítulos, o primeiro é o histórico e o segundo o das realizações da comissão/diretoria.

No primeiro capítulo, a história é explicada pela geografia, por isso o texto começa pela descrição do quadro natural pensando-a como moldura para ação do homem, inclusive vendo o tópos como construtor do perfil desse homem, que se adapta às planícies embrejadas. Essa adaptação permitiria dar inteligibilidade a "civilização" produzida pela conjugação da natureza com o homem. "O homem e o brejo" viviam em harmonia, pois havia equilíbrio nessa relação, induzindo a conformação de um grupo social específico.
"O grupo social da Baixada teve, durante sua evolução, atividade histórica à parte, no meio nacional. (...) Em nossa história, nenhum outro grupo é mais estável, mais sedentário, mais apegado a gleba nativa. Enquanto sertanistas, ardentes em ambição, desciam rios e varavam selvas, batendo, intrepidamente, todo o altiplano mediterrâneo, em busca de socavões e grupiaras, o fluminense, preocupado em desenvolver os seus currais e seus campos, nem ao menos vingara as serranias que muravam os confins de sua baixada. (GOES, 1939, p.14, grifo meu)

O motor dessa história não estava na luta de classes ou no desenvolvimento social do homem, mas no "combate permanente contra o pântano", ou seja, no saneamento, o equilibro desse homem com a natureza era o resultado, nas palavras do diretor, do domínio da cultura sobra a natureza, logo a história da Baixada é a história do saneamento.

Isolado na planície litorânea, à margem das lutas com o gentio, apático ao ouro e pedraria das minerações criou, entretanto, um dos mais belos núcleos de civilização agrária do Brasil.

A geografia continua escrevendo a história dos povos (...)

A história do povoamento da Baixada resume-se num combate permanente contra o pântano. (GOES, 1939, p.15, grifo meu)

Lendo a história pela ótica da luta constante para fazer das planícies embrejadas uma área desenvolvida economicamente, a decadência da região foi lida como a vitória da natureza sobre o homem. A construção de uma civilização e o seu declínio é a narrativa da história oficial que seria reproduzida exaustivamente. O relatório, junto com Maia Forte (1933), organizou a "versão definitiva" da História da Baixada Fluminense.

Todos os autores depois dos dois repetiriam a ideia de construção de uma civilização laboriosa, agrária por excelência, domando os brejos, desenvolvendo economicamente a região e formando uma aristocracia rural que entraria em decadência após a Abolição, já que em função da falta de mão de obra para continuar controlando o quadro natural, a Baixada voltou ao seu "estado primitivo".

A partir da constatação de que a região fora rica enquanto conseguira ter as terras saneadas, o autor do relatório passaria então enumerar as causas da insalubridade, de forma a construir as metas que 
deveriam ser atingidas pela Diretoria. Nessa narrativa tendo o saneamento como pano de fundo, os sujeitos passariam a ser as Comissões, e os fracassos das antecessoras, lidos como resultado da falta de uma visão técnica acerca das verdadeiras causas da insalubridade e da ausência de uma direção política, entendida pelo autor como desarticulação da governança/administração pública.

No curto texto apresentado, Goes indicava então a Comissão de 33/34 como solução definitiva para o saneamento da região, resgatando a antiga história e a "verdadeira vocação" do lugar. O texto não cita a Comissão Federal de 1910, mas reproduziu sua avaliação em dois aspectos, já que incorporou suas duas premissas: os leitos das ferrovias eram obstáculos ao escoamento das águas porque represavam as águas e as obras realizadas confirmariam a vocação agrícola da região, preditas nos estudos anteriores.

Preliminarmente, a execução das grandes obras hidráulicas, com conseqüente benéficos oriundos da melhoria das condições de salubridade e conquista de terrenos de fertilidade incontestável para a agricultura. (...) Finalmente, uma legislação espacial para incrementar a colonização e fomentar o desenvolvimento das culturas intensivas. (GOES, 1939, p.20, grifo meu)

O relatório indicou também, em poucas linhas, um conjunto de obras dividindo-o em cinco grupos: o de restauração, o de conservação, o de estudos, o de desobstrução e o das obras definitivas. A comissão formada em 1933 tinha apenas o objetivo de fazer os estudos e indicar o conjunto de intervenções para o saneamento definitivo da Baixada. Até este ponto do texto, apesar de já dividida as quatro seções, a referência espacial era toda a sua extensão, pois os objetivos e metas serviriam para toda a planície do estado.

A preocupação com as diferentes obras contra inundação e propriamente de saneamento foram estabelecidas nas ações, daí a divisão do que seriam obras de restauração, conservação, etc. Para a Comissão, apesar de interdependente, saneamento não era só combate as inundações, como explicita as palavras de Goes,
O saneamento da Baixada resume-se no enxaguamento dos extensos brejais originados pela extravazão dos rios durante a estação chuvosa. (...) Sanitariamente, nenhum mal deveria advir dos transbordamentos, si, ao fim de pouco tempo, as águas retornassem às calhas fluviais, de onde, momentaneamente, se apartaram. (...) Entretanto, para o aproveitamento agrícola da terra é frequentemente indispensável evitar a inundações (GOES, 1939, p.23)

Desta forma, saneamento, assim como para a comissão de 1910, seria instrumento de desenvolvimento econômico da região. No relatório de 1939 foi confirmado que as intervenções foram realizadas pela Diretoria depois de 1935 e estas se deram em função dos estudos da Comissão, entretanto, o mesmo texto confirmava que somente depois da limpeza dos principais rios foi possível conhecer de fato a região sobre a qual a diretoria deveria intervir e isto ocorreu depois de 36, logo é necessário analisar o alcance da comissão e por que seus estudos tornaram-se referência.

Durante a intervenção da Diretoria na região seis problemas apareceram, eles foram listados no segundo capítulo, assim como as realizações até aquele momento. É possível neste capítulo vislumbrar uma noção de planejamento no território da planície do estado, principalmente na seção Guanabara, já que ancorada numa visão histórica calcada no resgate da vocação econômica da região o saneamento traria de volta toda a pujança perdida.

O Estudo e as intervenções descritos no relatório dão conta que a Baixada da Guanabara foi a principal região de atuação da Diretoria, já que recebeu o maior número de obras, e que a ideia de organizar um conjunto de ações em um território específico não foi coincidência, mas estava ligada aos interesses que não estavam na esfera estritamente técnica e que em última instância deveriam ser articuladas também a ação do Departamento da Municipalidade que promoveu a confecção de "planos urbanisticos" para várias cidades do estado do Rio de Janeiro.

O governo federal através da Diretoria de Saneamento e o governo estadual através do interventor e do Departamento das Municipalidades, durante o Estado Novo, momento do relatório, agiram de forma combinada sobre o território fluminense, 
ainda que as ações parecessem fragmentadas e dispersas. Não se pode pensar que a dragagem da bacia do rio Iguaçu pela diretoria não tivesse articulação com o plano de urbanização de Nova Iguassu mostrado na Exposição das Municipalidades em 1942 sob os auspícios do departamento.

Havia durante o Estado Novo uma leitura sobre quais seriam as potencialidades econômicas do estado do Rio, que o relatório na sua última parte reproduziu, utilizando inclusive o tom ufanista. Goes repetiu os principais conceitos que mobilizaram o pensamento social durante a ditadura em seu relatório, pois para o engrandecimento do país era necessário fortalecimento dos estados a partir das suas potencialidades econômicas sob a gerência do poder central, tradutor e condutor do destino da nação.

Da mesma forma que ações dispersas no território brasileiro podem ser conjugadas ao ideário estadonovista, tais como Marcha para o Oeste e o surgimento de várias comissões de planos e os planos nas principais cidades brasileiras, a atuação da Diretoria na Baixada, especificamente na da Guanabara também pode ser lida sob esse parâmetro, principalmente no que se refere a inserção do território fluminense na modernidade preconizada pelo estado (em suas múltiplas repartições)

Modernização e modernidade são conceitos diferentes, mas no Estado Novo ambos foram articulados à construção da Nação, neste sentido o saneamento era visto na região como instrumento de modernidade e base para modernização, um exemplo disto foi o item do relatório cujo titulo "obras de arte" nada mais era que a lista dos maquinários de última geração à disposição da Diretoria, indicando que a repartição pública tinha todos os instrumentos necessários para realizar o "progresso" almejado. Nas áreas definitivamente saneadas (em 39) foram abertas estradas de rodagem e houve estímulo à agricultura através das colônias agrícolas na Baixada, ações que em um pequeno espaço estavam em sintonia com a construção da ideia de Brasil Moderno.

O processo de dragagem e dessecamento era monumental, ele próprio refletia a vontade de progresso, não como o apagamento do passado colonial, mas como retorno aos tempos áureos sob a égide do governo centralizador. Em Nova Iguassu, a citricultura traduzia com desenvoltura essa potencialidade, explicitada no último parágrafo do relatório: "Pela imensa riqueza, a Baixada Fluminense é digna das obras gigantescas que o governo está executando e que tornarão em pouco tempo, essa grande área uma das maiores fontes de produção do Brasil" (GOES, 1939, p.68)

\section{Ainda algumas considerações acerca da construção da ideia de região}

A pesquisa ainda está no início, mas duas observações podem ser feitas sobre a Diretoria chefiada pelo engenheiro Hildebrando Goes. A primeira é que Comissão e Diretoria devem ser entendidas como unidade, e como comissão de estudos foi eficiente, principalmente na construção de um discurso acerca da história da região. A comissão teve sucesso no objetivo de organizar todas as informações existentes sobre a Baixada, daí o relatório de 1934 ter sido minucioso e fartamente utilizado pelos historiadores e memorialistas locais, mesmo sem citálo. A Diretoria que a sucedeu conseguiu fazer um conjunto de obras, que de fato ampliaram o uso das terras da Baixada, em sua grande maioria não sendo utilizada para a agricultura, mas para a ocupação urbana, incorporando-a definitivamente à malha urbana carioca.

O saneamento da Baixada potencializou o processo de periferização, sem que uma palavra sobre urbanização fosse colocada no relatório de 1939. A própria ação de saneamento apontou os limites da modernização preconizada pelo Estado Novo no qual a Diretoria estava perfilada e refletia. Sempre associada aos maquinários modernos domando a natureza, construindo uma civilização moderna nas planícies embrejadas, o relatório não escondeu que para o funcionamento das dragas era necessário inicialmente o trabalho manual de homens atolados até o pescoço na lama.

Não se pode pensar a Comissão sem associá-la à Diretoria (e vice-versa), já que a primeira ficou na 
alçada dos estudos, enquanto a segunda colocou em prática as sugestões preconizadas pela primeira, mas ao fazer isto foi possível descortinar as intenções políticas e o ideário civilizatório que estavam atrelados a sua atuação na Baixada, que em 1934 não estavam claramente explicitados como estariam em 39.

A Diretoria utilizando o corpus documental da Comissão e sob a chefia do mesmo engenheiro empreenderia a inserção da região naquilo que ele denominou de Brasil Grande e Moderno, mas essa integração se deu através da dinâmica que ele ajudou a construir cujo resultado foi a "Baixada para os de baixo".

Na década de 1920, a área era lida a partir dos problemas de insalubridade, mas ainda não tinha um discurso hegemônico de como seria possível resolvêlos. Na década de 40, esse discurso foi construído sob os auspícios da atuação da Comissão/ Diretoria, utilizando-se de um repertório já conhecido e, ainda que não desse conta das dinâmicas territoriais existentes, sejam aquelas voltadas à urbanização acelerada ou às da citricultura, traduziu e organizou um conjunto de representações permitindo aquele território ser lido como região.

Atualmente a Baixada Fluminense é vista como uma área específica dentro da região metropolitana, ou seja, uma sub-região. Sua ocupação ocorreu de forma intensa depois da década de 1940 com o fim da citricultura em função da articulação de duas ações promovidas pelo governo federal: uma voltada à eletrificação da principal ferrovia da região, juntamente com a instituição do preço único da passagem dos trens da Central do Brasil e a outra voltada às grandes obras de dragagem, tornaram possível a ocupação de uma vasta extensão de terra antes alagada; subsidiariamente ratificou uma narrativa sobre a Baixada e esta, em última instância, entre outras coisas, cimentou uma rede de convenções e de rotinas que se transmutaram rapidamente em "tradição inventada" (HOBSBAWM e RANGER, 2006).

A população que ocupou essas terras não tinha nenhuma relação de continuidade/descontinuidade

\footnotetext{
${ }^{2}$ No sentido dado por Hobsbawm e Ranger (2006) em seu livro "invenção das tradições" quando estudam alguns
}

com o passado do lugar, pois a maioria era formada de (i)migrante recém-chegado, mas assistiu e foi a principal beneficiária das obras de saneamento realizadas pela Diretoria, não só usufruindo do aumento do estoque de terras que gerou inúmeros loteamentos, como também da redução drástica das doenças endêmicas. Ao se fixarem na nova terra esses habitantes incorporaram o enredo de uma história que fazia sentido para um pequeno grupo que ali vivia, mas ao traduzirem em seu cotidiano esse repertório, delimitaram formalmente e espacialmente essa história, "inventando a Baixada Fluminense"2.

Ao término da leitura do livro/relatório constituído em 1939 pode-se concluir, pelo menos discursivamente, que a área contígua à cidade do Rio de Janeiro, especificamente a então Baixada da Guanabara, estava preparada para adentrar em uma era de progresso como espaço rural moderno, não só como cinturão verde do Distrito Federal, mas como grande centro exportador de produtos agrícolas, no caso a laranja. A Diretoria auferia ao território, basicamente ocupado pelo grande município de Nova Iguaçu, o seu lugar no projeto de construção da nação preconizado pelo Estado Novo de duas formas: como modelo a ser seguido e parceiro produtivo.

A história utilizada servia para legitimar as ações da Diretoria e garantia os objetivos preconizados pelo Estado Novo, mas o que se assistiu na prática, já no ano seguinte, foi a queda das exportações das laranjas (em função da Segunda Guerra) e depois nos anos de 1950, a região ser absorvida como célula (sub) urbana da cidade do Rio, com três distritos emancipados do grande município. Com uma história consolidada, uma identidade começaria a ser conformada e com ela uma região. Levaria algumas décadas para que essa identidade pudesse ser apropriada politicamente, seja na criação do Dia da Baixada Fluminense ou nas secretarias (ou subsecretarias) estaduais que passaram a existir na década de 1990, especificamente para intervir na região.

Ao buscar apresentar/discutir o relatório como uma das maquinarias discursivas utilizadas no

costumes institucionalizados depois da Revolução Industrial 
processo de conformação de uma região, deseja-se ressaltar que o relatório não construiu a região, mas sem dúvida, introduziu um discurso produtor de realidade que mais tarde seria usado na constituição de uma sensibilidade social em relação ao espaço, potencializando a emergência Baixada Fluminense enquanto região.

Dito de outra forma, reconhecendo que ideia de região é uma invenção histórica que toma o território, em algum momento, como um dado natural e que passa a utilizar as narrativas produzidas sobre ele como espelhos da realidade e não como instrumento de criação, eles próprios, desta realidade, esconde sob uma pretensa naturalidade um discurso político social. Da mesma forma que a Grande Seca de 1877 tornouse paradigma natural de inauguração do Nordeste, a planície embrejada no entorno da Corte passaria a ser visto como foco de doenças inaugurando a Baixada, na mesma década. Neste sentido, o Estado é o espaço privilegiado onde as práticas discursivas são regularizadas, seja pela fantasia da neutralidade técnica, seja por esconder redefinições políticas que estão no bojo do recorte espacial.

Aquelas terras baixas com rios e pequenos morros puderam ser nomeadas de Baixada, entre os anos de 1870 e 1940, e depois Fluminense (na década de 1970) a partir de um longo processo de gestação, que longe de ser sincrônico, comportou um difuso (e extenso) embate de códigos e sentidos, arregimentando um conjunto de significados. Hildebrando com sua atuação na Comissão/Diretoria representou um momento nesse processo cujo ápice seria dado pela FUNDREM em 1975 com a sua UUIO (Unidades Urbanas Integradas do Oeste), esta sim formalizando a "invenção da Baixada Fluminense".

A importância desta discussão atualmente ocorre em função dos inúmeros investimentos que ocorreram na RMRJ e em especial na Baixada Fluminense por conta do PAC, tais como arco metropolitano e PMCMV, que atuaram na região como se esta fosse um fato inerte da natureza. As políticas públicas partem desta concepção, considerando-a uma unidade de realidade e não um recorte, um pedaço de história, enfim um fato humano, e como tal repleto de políticas e intencionalidades, às vezes totalmente descoladas das demandas sociais dos que ali vive. Mas essa é outra discussão....

\section{Referências}

1 ALBUQUERQUE JUNIOR, D. M de. A invenção do Nordeste e outras artes. 4 ed. São Paulo: Cortez ed, 2009

2 ALVES, J C S. Dos barões ao extermínio: uma história da violência na baixada Fluminense. Duque de Caxias: APPH/CLIO, 2003

3 AUGÉ, M. Não Lugares: uma introdução a antropologia da supermodernidade. 7ed. Campinas: Papirus, 2008

$4 \quad$ BRAZIL. Recenseamento do Brazil em 1872. Rio de Janeiro: Typ. G Leuzinger, vol10 Rio de Janeiro, $1874 . \quad$ Disponível em: http://biblioteca.ibge.gov.br/visualizacao/livros/liv 25477.pdf Acesso em: 30 maio 2013

5 BRASIL, Diretoria Geral de Estatística. População Recenseada em 31 de dezembro de 1890. vol.4. Rio de Janeiro: Oficina de Estatística, 1898. Disponível em: http://biblioteca.ibge.gov.br/visualizacao/livros/liv 25487.pdf Acesso em: 30 maio 2013

$6 \quad$ BRASIL, Diretoria Geral de Estatística. População Recenseada em 1 de setembro de 1920. Rio de Janeiro: Typ. da Estatística, 1922. Disponível em: http://biblioteca.ibge.gov.br/visualizacao/livros/liv 6462.pdf Acesso em: 30 maio 2013

7 BRASIL, IBGE. Censo Demográfico de 1940, série regional Rio de Janeiro. Rio de Janeiro: Serviço Gráfico do IBGE, 1951. Disponível em: https://biblioteca.ibge.gov.br/visualizacao/periodi cos/65/cd 1940 v2 br.pdf Acesso em: 5 março 2013.

8 FORTE, J M M. Memória da fundação de Iguassu. Rio de Janeiro: Typ. do Jornal do Comercio Rodrigues e Cia, 1933.

9 GOES, H de A. O Saneamento da Baixada Fluminense. Rio de Janeiro: MVOP/DSBF, 1939.

10 HOBSBAWM, E e RANGER, T. A invenção das tradições. Tradução de Celina C Cavalcanti. 4ed. São Paulo: Paz e Terra, 2006.

11 MACHADO, R. Foucault: ciência e saber. 3 ed. RJ: Jorge Zahar ed, 2006

12 MEDEIROS, O. Administração territorial: comentários, subsídios e novas leis. Rio de Janeiro: Imprensa Nacional, 1946

13 PECHEUX, M. Semântica e discurso: uma crítica à afirmação do óbvio. $5^{a}$ ed. Tradução Eni 
Puccinelli Orlandi e outros. Campinas: ed. Unicamp, 2014

14 PEREIRA, W. A mudança da vila: história iguaçuana. Duque de Caxias: Arsgrafica/IHGNI, 1970.

15 REZENDE, V (org). Urbanismo na era Vargas: a transformação das cidades brasileiras. Niterói: edUFF/ Intertexto, 2012.

16 RIO DE JANEIRO. Legislação sobre municípios, comarcas e distritos. Organizada por Desidério Luiz de Oliveira Junior. Rio de janeiro: Typ. Do jornal do comercio de Rodrigues e C, 1926.

17 RIO DE JANEIRO. Mensagem do Presidente do Estado do Rio de Janeiro, ano de 1927, apresentado à Assembleia Legislativa. Rio de Janeiro: Typ. Do jornal do Comercio de Rodrigues e C. 1927. Disponível em: http://brazil.crl.edu/bsd/bsd/u889/000002.html. Acesso em 5 mar 2013

18 SOARES, M T de S. Nova Iguaçu: absorção de uma célula urbana pelo Grande Rio de Janeiro. In: Revista Brasileira de Geografia. Rio de Janeiro: IBGE, vol. 2, n. 24, 1962.

19 SOUZA, S M de. Da Laranja ao Lote: Transformações sociais em Nova Iguaçu. Rio de Janeiro, UFRJ, PPGAS/ Museu Nacional, 1992. (Dissertação de Antropologia)

20 TORRES, G (org). Baixada Fluminense: a construção de uma história, sociedade, economia e sociedade. São João de Meriti: IPABH, 2004. 